\title{
Doses de bokashi em cobertura na produção de beterraba
}

\author{
Priscilla Nátaly de Lima Silva ${ }^{1}$, Natália de Brito Lima Lanna ${ }^{1}$, Antonio Ismael Inácio \\ Cardoso ${ }^{1}$
}

${ }^{1}$ Universidade Estadual Paulista "Júlio de Mesquita Filho", Câmpus de Botucatu, São Paulo, Brasil. E-mail: priscilla_nataly@hotmail.com, nataliabllanna@gmail.com, ismaeldh@fca.unesp.br

Recebido: 05/07/2017; Aceito: 25/01/2018

\section{RESUMO}

A produção orgânica de hortaliças tem apresentado crescimento constante. Porém, ainda há necessidade de pesquisas em algumas etapas da produção, como a adubação. Na cultura da beterraba, são escassas as informações sobre a adubação orgânica em cobertura. Desta forma, objetivou-se com este trabalho avaliar a influência de doses de bokashi aplicadas em cobertura na produção de beterraba. Foram realizados dois experimentos na Fazenda Experimental São Manuel (FCA/UNESP) e estudadas cinco doses de bokashi em cobertura (0, 150, 300,450 e $600 \mathrm{~g} \mathrm{~m}^{2}$ ) e uma testemunha com cobertura inorgânica, utilizando-se um delineamento experimental de blocos ao acaso, com quatro repetições. No primeiro experimento, a adubação de plantio constou apenas de composto orgânico e no segundo, além do composto orgânico foi realizada a adubação inorgânica com NPK 4-14-8. As características avaliadas foram: altura da planta, massa da matéria fresca e seca da parte aérea e raiz, diâmetro e comprimento da raiz e produtividade. A aplicação de até $600 \mathrm{~g} \mathrm{~m}^{-2}$ de bokashi em cobertura proporcionou incremento na altura da planta, massa da matéria fresca de raiz, comprimento de raiz e produtividade da beterraba nos dois experimentos: com e sem adubação inorgânica no plantio. A adubação de plantio orgânica quando associada à inorgânica apresentou os melhores resultados dos caracteres avaliados, quando comparada à orgânica.

Palavras-chave: adubação de cobertura, adubação orgânica, Beta vulgaris, produtividade

\section{Bokashi rates in topdressing in the beet production}

\begin{abstract}
Vegetable organic production has shown steady growth. However, it still needs research at some stages of production, such as fertilization. In the beet crop, information on the organic fertilization in topdressing is scarce. Thus, objective of this study was to evaluate the influence of doses of bokashi applied in top dressing in the production of beet. Two experiments were conducted at the Experimental Farm São Manuel (FCA/UNESP), with five rates in topdressing were tested $\left(0,150,300,450\right.$ and $\left.600 \mathrm{~g} \mathrm{~m}^{-2}\right)$, and a control with inorganic fertilization in topdressing, using a randomized blocks experimental design, with four replications. In first experiment, the planting fertilization consisted only of organic compost, and, in second one, besides the organic compost was carried out the inorganic fertilization with NPK 4-14-8. The following characteristics were evaluated: plant height, fresh and dry weight of the shoot and the root, root diameter and length, and yield. The application of up to $600 \mathrm{~g} \mathrm{~m}^{-2}$ of bokashi in top dressing resulted in an increase in plant height, fresh weight of root, root length and beet yield in both experiments: with and without inorganic fertilizer at planting. The organic fertilization when associated to inorganic presented the best results of the evaluated characters, when compared to organic.
\end{abstract}

Key words: top dressing, organic fertilizer, Beta vulgaris, yield. 


\section{Introdução}

A beterraba (Beta vulgaris L.) é uma das 17 hortaliças propagadas por sementes mais importantes no Brasil, sendo uma cultura bienal herbácea, típica de clima temperado, que apresenta excelente valor nutritivo na parte aérea e raiz, apresentando altos valores de ferro, sódio, potássio, vitamina $\mathrm{A}$ e do complexo B. Seu cultivo pode ter como finalidade a produção de açúcar, forragem ou para mesa (consumo humano), sendo que no Brasil, prevalece a produção para mesa (TIVELLI et al., 2011).

Segundo Filgueira (2008), os solos mais favoráveis ao cultivo de beterraba são de textura média ou argilosa, desde que friáveis, bem drenados e ricos em matéria orgânica. Entre os macronutrientes que proporcionam o aumento da produtividade da cultura, destacam-se o nitrogênio $(\mathrm{N})$ que promove a expansão foliar e o acúmulo de massa e o potássio $(\mathrm{K})$, que favorece a formação e translocação de carboidratos e uso eficiente da água pela planta; ainda melhora a qualidade do produto, entre outros (FILGUEIRA, 2008; TIVELLI et al., 2011).

No cultivo de olerícolas, em curtos períodos de tempo, as culturas apresentam elevada produtividade, ocorrendo grande exportação de nutrientes com as colheitas. Desta forma, geralmente são realizadas adubações orgânicas (SOUZA; RESENDE, 2014), visando melhorar as condições físicas, químicas e biológicas dos solos, e aumentar a disponibilidade de nutrientes ao longo do ciclo da cultura.

A adubação orgânica faz parte de um sistema de produção que vem crescendo nos últimos anos: a chamada agricultura sustentável. Os alimentos oriundos deste cultivo representam o resgate da agricultura tradicional, a favor da sustentabilidade, buscando produtos mais saudáveis e evitando o risco da contaminação com agrotóxicos (MOOZ; SILVA, 2014).

Com relação à beterraba, são escassas as informações na literatura referente ao uso de adubos orgânicos em cobertura; há apenas recomendações sobre fertilização química. Uma possível alternativa seria a utilização do adubo orgânico bokashi, visto que o mesmo eleva o teor de nitrogênio, fósforo e potássio no solo (OURIVES et al., 2010) e seus nutrientes são disponibilizados sob a forma de quelatos, isto é, estão presos nas estruturas orgânicas e não se perdem por lixiviação e volatilização após a aplicação, sendo esta uma grande vantagem. Para a produção do bokashi são utilizadas matérias-primas como farelos de diversos cereais, oleaginosas e farinhas de origem animal. Este adubo ainda favorece a vida microbiana no solo que por sua vez promove a ciclagem de nutrientes e sua liberação para a nutrição das plantas. Esse fator favorece tanto os produtores convencionais, que buscam recuperar a vitalidade de seus solos, como os produtores que visam um cultivo sustentável (SIQUEIRA; SIQUEIRA, 2013).

De acordo com Trani et al. (1997) a cultura da beterraba, necessita na adubação de cobertura de nitrogênio e potássio para seu desenvolvimento, sendo que o bokashi supre esta necessidade. Apesar do aumento da produção sustentável nos últimos anos, são escassos os estudos com adubação orgânica de cobertura. Sendo assim, objetivou-se com este trabalho avaliar a influência de doses de bokashi aplicados em cobertura na produção de beterraba.

\section{Material e Métodos}

Os experimentos foram desenvolvidos na Fazenda Experimental São Manuel, área pertencente à Faculdade de Ciências Agronômicas (FCA) da Universidade Estadual Paulista (UNESP), Campus de Botucatu. O clima da região de São Manuel-SP, conforme os critérios adotados por Köppen, é Cfa (Clima Temperado Mesotérmico). No período dos experimentos, 11/05/2012 a 17/09/2012, a pluviosidade acumulada foi de $234,5 \mathrm{~mm}$ e as médias das temperaturas máxima, média e mínima foram de 25,$9 ; 16,6$ e $7,9^{\circ} \mathrm{C}$, respectivamente.

Foram realizados dois experimentos nos quais foram avaliadas a influência de doses de bokashi em cobertura na produção de beterraba, sendo que no primeiro experimento foi utilizada apenas a adubação orgânica no plantio; no segundo experimento foi utilizada a adubação orgânica associada à inorgânica. Em ambos experimentos se utilizou o delineamento experimental de blocos ao acaso, com seis tratamentos e quatro repetições. Foram utilizadas cinco doses de bokashi $(0$, $150,300,450$ e $600 \mathrm{~g} \mathrm{~m}^{-2}$, que correspondem a $0 ; 1,5$; 3,0; 4,5 e 6,0 $\mathrm{Mg} \mathrm{ha}^{-1}$ ) em cobertura, e um tratamento testemunha com adubação inorgânica em cobertura (129 $\mathrm{g} \mathrm{m}^{-2}$ de sulfato de amônio $+24 \mathrm{~g} \mathrm{~m}^{-2}$ de cloreto de potássio, que correspondem a 1,29 $\mathrm{Mg} \mathrm{ha}^{-1}$ de sulfato de amônio e 0,24 $\mathrm{Mg} \mathrm{ha}^{-1}$ de cloreto de potássio), de acordo com a recomendação de Trani et al. (1997).

O solo da área de cultivo considerado Latossolo Vermelho distrófico típico, de textura arenosa (EMBRAPA, 2013) na análise química apresentou os valores de $\mathrm{pH}\left(\mathrm{CaCl}_{2}\right)=6,0$; M.O. $=13 \mathrm{~g} \mathrm{~m}^{-3} ; \mathrm{P}_{\text {resina }}=$ $82 \mathrm{mg} \mathrm{dm}^{-3} ; \mathrm{H}+\mathrm{Al}=13 \mathrm{mmol}_{\mathrm{c}} \mathrm{dm}^{-3} ; \mathrm{K}=2,1 \mathrm{mmol}_{\mathrm{c}} \mathrm{dm}$ ${ }^{3} ; \mathrm{Ca}=36 \mathrm{mmol}_{\mathrm{c}} \mathrm{dm}^{-3} ; \mathrm{Mg}=11 \mathrm{mmol}_{\mathrm{c}} \mathrm{dm}^{-3} ; \mathrm{SB}=48$ $\mathrm{mmol}_{\mathrm{c}} \mathrm{dm}^{-3}, \mathrm{CTC}=61 \mathrm{mmol}_{\mathrm{c}} \mathrm{dm}^{-3}$ e V\% $=80$.

A calagem não foi necessária, pois a saturação por bases expressa no resultado da análise foi de $80 \%$, sendo esse o valor recomendado para o cultivo da beterraba (TRANI et al., 1997). Com base na análise química do solo, no dia 04 de junho de 2012 foram realizadas as adubações de plantio com $40 \mathrm{Mg} \mathrm{ha}^{-1}$ de composto orgânico (base úmida) no primeiro 
experimento, e $40 \mathrm{Mg} \mathrm{ha}^{-1}$ de composto orgânico mais 1,3 $\mathrm{Mg} \mathrm{ha}^{-1}$ do formulado NPK (4-14-8) no segundo experimento, seguindo a recomendação de Trani et al. (1997).

A adubação em cobertura foi parcelada em três vezes nos dois experimentos, sendo aplicada em intervalos de 14 dias após o transplante, nas seguintes datas: 25/06; 09/07 e 23/07/2012. Para a adubação de plantio foi utilizado o composto orgânico da empresa Visafértil $^{\circledR}$ e para adubação em cobertura, o fertilizante orgânico farelado Bio Bokashi da empresa Ophicina Orgânica Fertilizantes, constituído por farinha de peixe, farinha de osso, minerais de rocha, farelo de arroz, melaço e carvão. Estes materiais foram analisados como fertilizantes orgânicos e organominerais destinados à aplicação via solo segundo metodologia do MAPA (2014) e os resultados encontram-se na Tabela 1.

Foi utilizado o híbrido Kestrel da empresa Sakata ${ }^{\circledR}$ Seed Sudamerica Ltda; a semeadura foi realizada no dia 11/05/2012 em bandejas de poliestireno expandido de 200 células, contendo substrato para hortaliças. As mudas foram transplantadas no dia 11/06/2012 para canteiros de 1,00 m de largura, totalizando quatro linhas no sentido longitudinal, espaçadas em 0,25 m entre linhas e $0,10 \mathrm{~m}$ entre plantas. Foram utilizadas 40 plantas por parcela de $1 \mathrm{~m}^{2}$, sendo que somente 10 plantas das fileiras centrais constituíram a parcela útil e as demais utilizadas como bordaduras.

O controle de plantas daninhas foi realizado através de capinas manuais ao longo do ciclo da cultura. Foi utilizado o sistema de irrigação por aspersão. Não houve necessidade do controle químico de pragas e doenças. A colheita para avaliação da produção foi realizada manualmente e uma única vez no dia 17/09/2012.

Nos dois experimentos foram avaliadas, em uma amostra de 10 plantas por parcela, as seguintes características: a) altura das plantas $(\mathrm{cm})$; distância entre a superfície do solo e a parte mais alta da planta; b) massa da matéria fresca e seca da parte aérea e da raiz (g), sendo esta determinada após a secagem dos materiais em estufa de circulação de ar forçada a $65^{\circ} \mathrm{C}$ até atingir massa constante e pesada em balança digital de 0,1 g de precisão; c) comprimento e diâmetro das raízes com auxílio de um paquímetro digital; d) produtividade: obtida com a transformação dos dados de massa média da raiz em $\mathrm{Mg} \mathrm{ha}{ }^{-1}$, em função da população de plantas (307.692 plantas ha $\left.{ }^{-1}\right)$, sendo esta estimada pelo espaçamento entre fileiras de $0,25 \mathrm{~m}$, $0,10 \mathrm{~m}$ entre plantas e o espaçamento entre canteiros de $0,3 \mathrm{~m}$.

Os dados foram submetidos à análise de variância e de regressão. A relação entre os quadrados médios do resíduo (RQMR) das análises de variâncias individuais dos experimentos não ultrapassaram a relação de 7:1 permitindo, portanto, a realização da análise conjunta dos experimentos (BANZATTO; KRONKA, 2006), para comparar as áreas sem adubação inorgânica e com adubação inorgânica no plantio. Todas as análises foram realizadas com o programa SISVAR (FERREIRA, 2011) a $5 \%$ de probabilidade.

\section{Resultados e Discussão}

Os resultados obtidos mostram que as doses de bokashi em cobertura não apresentaram efeito significativo na massa fresca $(28,73 \mathrm{~g})$ e seca $(2,73 \mathrm{~g})$ da parte aérea e massa seca da raiz $(10,91 \mathrm{~g})$, no primeiro experimento sem adubação inorgânica no plantio. $O$ segundo experimento, com adubação inorgânica, também não apresentou diferença significativa para as mesmas características que o experimento 1, apresentando médias $25,85 \mathrm{~g} ; 2,28 \mathrm{~g}$; $8,41 \mathrm{~g}$, para massa fresca e seca da parte aérea e massa seca de raiz, respectivamente (Tabela 2 ).

Para altura de plantas verificou-se aumento linear em função das doses de bokashi em cobertura, com maior valor $(21 \mathrm{~cm})$ para a dose de $600 \mathrm{~g} \mathrm{~m}^{-2}$ sem adubação inorgânica no plantio. Neste experimento para cada $100 \mathrm{~g} \mathrm{~m}^{-2}$ de bokashi houve um aumento de $0,7 \mathrm{~cm}$ (Figura 1A).

Tabela 1. Análise química do composto orgânico Visafértil ${ }^{\circledR}(\mathrm{CO})$ e do Bio Bokashi (BBO) utilizados nos experimentos. FCA/UNESP, Botucatu-SP, 2012

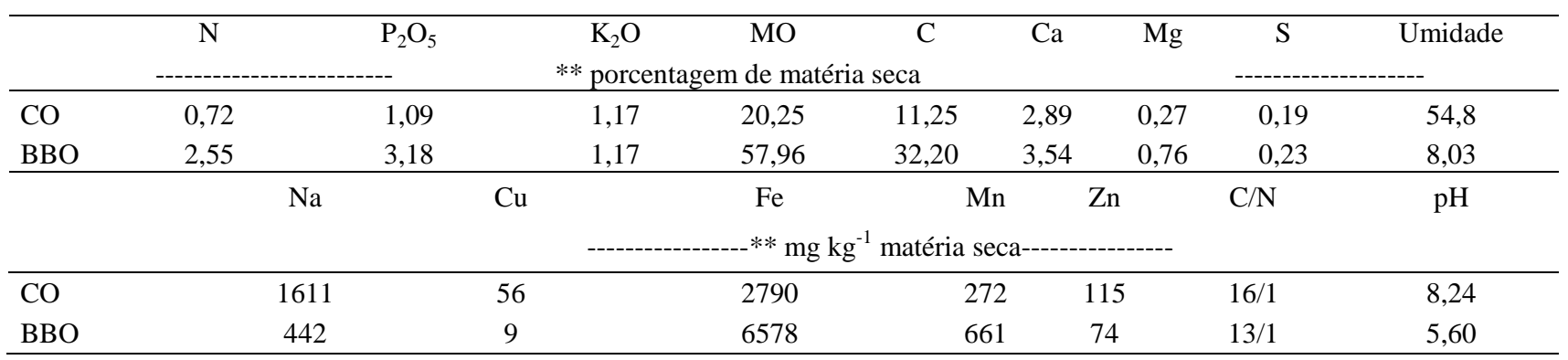

Fonte: Laboratório de análise de solos do Departamento de Solos e Recursos Ambientais - FCA/UNESP. 
Tabela 2. Massa da matéria fresca da parte aérea (MFPA), massa da matéria seca da parte aérea (MSPA) e raiz (MSR) da planta de beterraba, em função das doses de bokashi em cobertura, sem e com adubação inorgânica no plantio nos experimentos I e II. FCA/UNESP, São Manuel-SP, 2012

\begin{tabular}{|c|c|c|c|c|c|c|}
\hline \multirow{3}{*}{$\begin{array}{l}\text { Doses de bokashi } \\
\qquad\left(\mathrm{g} \mathrm{m}^{-2}\right)\end{array}$} & \multicolumn{2}{|c|}{$\begin{array}{c}\text { MFPA } \\
(\mathrm{g})\end{array}$} & \multicolumn{2}{|c|}{$\begin{array}{c}\text { MSPA } \\
(\mathrm{g})\end{array}$} & \multicolumn{2}{|c|}{$\begin{array}{c}\text { MSR } \\
(\mathrm{g})\end{array}$} \\
\hline & \multicolumn{6}{|c|}{....................................Adubação inorgânica de plantio................... } \\
\hline & Sem & Com & Sem & Com & Sem & Com \\
\hline 0 & 23,8 & 25,8 & 2,48 & 2,93 & 8,15 & 10,12 \\
\hline 150 & 20,8 & 25,2 & 1,90 & 2,10 & 6,84 & 8,00 \\
\hline 300 & 27,6 & 32,2 & 2,50 & 2,92 & 7,88 & 12,58 \\
\hline 450 & 26,7 & 32,0 & 2,01 & 2,41 & 8,61 & 11,82 \\
\hline 600 & 30,2 & 28,2 & 2,54 & 3,28 & 10,58 & 12,07 \\
\hline $\mathrm{F}$ & $1,45^{\mathrm{ns}}$ & $1,78^{\mathrm{ns}}$ & $0,44^{\mathrm{ns}}$ & $1,85^{\mathrm{ns}}$ & $0,68^{\mathrm{ns}}$ & $1,92^{\mathrm{ns}}$ \\
\hline CV (\%) & 23,26 & 17,27 & 39,91 & 25,22 & 39,43 & 24,86 \\
\hline
\end{tabular}

A.

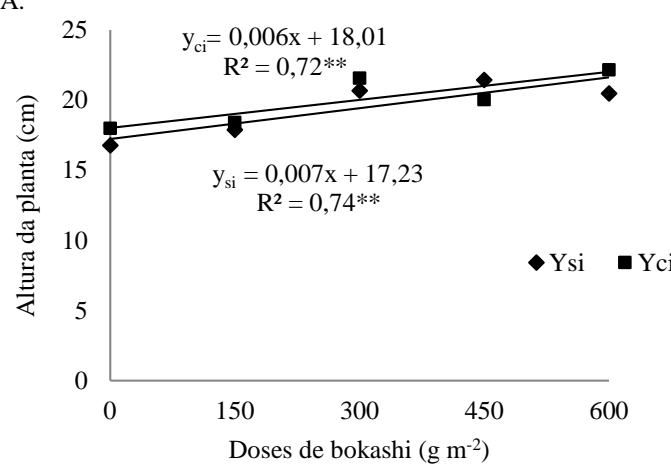

C.

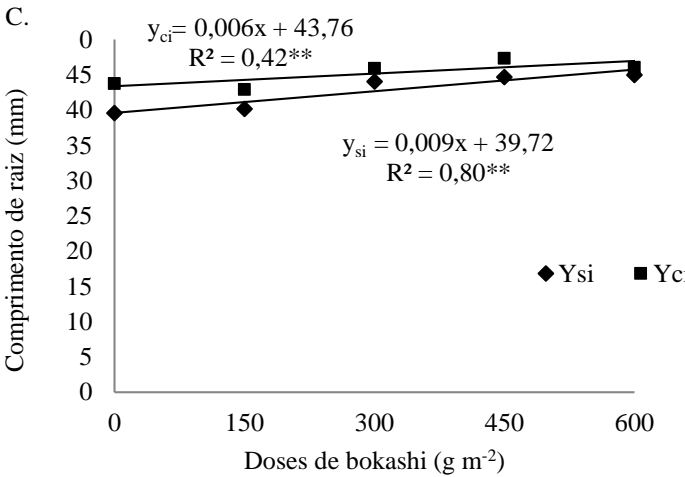

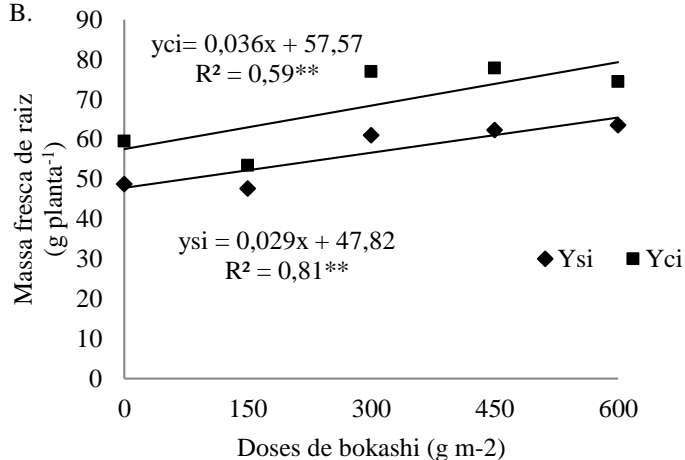

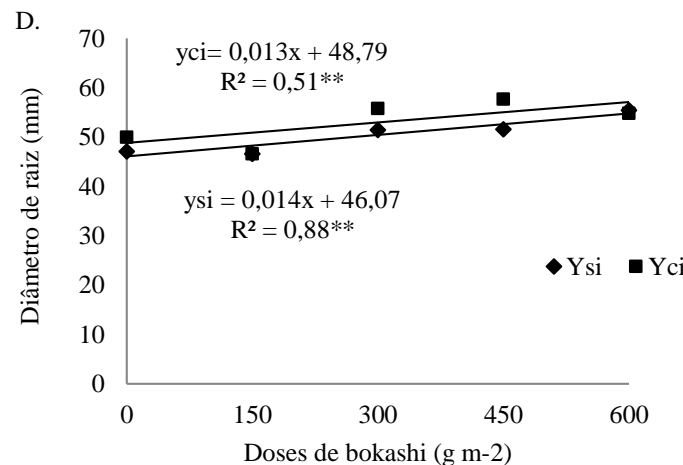

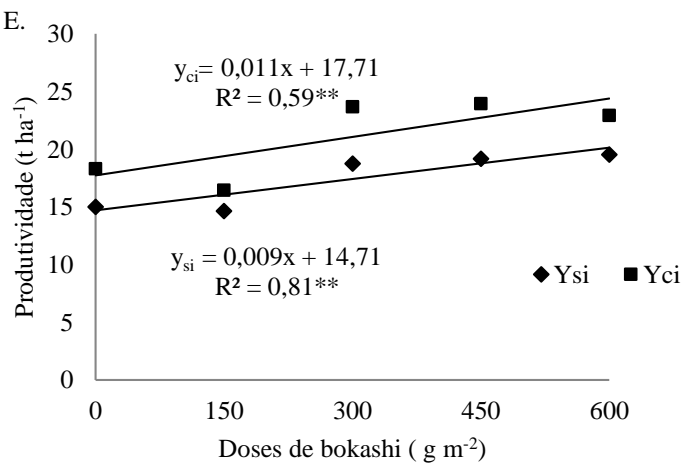

Figura 1. Altura da planta (A), massa fresca da raiz (B), comprimento (C) e diâmetro (D) de raiz e produtividade (E) das plantas de beterraba na colheita, em função das doses de bokashi em cobertura, sem (Ysi) e com (Yci) adubação inorgânica no plantio. FCA/UNESP, São Manuel-SP, 2012. ${ }^{* *}=$ significativo a 5\% de probabilidade. 
A altura observada neste trabalho foi inferior a encontrada por Silva et al. (2016), onde a maior altura de planta de beterraba foi $30,5 \mathrm{~cm}$, sem adubação inorgânica no plantio, aplicando até $600 \mathrm{~g} \mathrm{~m}^{-2}$ de torta de mamona em cobertura.

No experimento com adubação inorgânica no plantio houve aumento linear e a dose de $600 \mathrm{~g} \mathrm{~m}^{-2}$ proporcionou a maior altura de plantas, atingindo 22 $\mathrm{cm}$. Para cada $100 \mathrm{~g} \mathrm{~m}^{-2}$ de bokashi há um aumento de $0,6 \mathrm{~cm}$ na altura de plantas (Figura 1A).

A massa da matéria fresca de raiz apresentou aumento linear nos dois experimentos, com aumento de 2,9 g e 3,6 g para cada $100 \mathrm{~g} \mathrm{~m}^{-2}$ de bokashi, sem e com adubação inorgânica de plantio, respectivamente (Figura 1B). Estes dados diferem do encontrado por Silva et al. (2016), onde o aumento linear da matéria fresca da raiz da beterraba ocorreu apenas na ausência de adubação inorgânica no plantio, utilizando até $600 \mathrm{~g} \mathrm{~m}^{-2}$ de torta de mamona na adubação de cobertura. Já Barreto et al. (2013) verificaram que as massas das raízes das beterrabas não foram influenciadas pelas doses de nitrogênio aplicadas em cobertura.

Houve aumento linear no comprimento da raiz; com a maior dose obteve-se $44,9 \mathrm{~mm}$ e $46,0 \mathrm{~mm}$, sem e com adubação inorgânica no plantio, respectivamente. O aumento foi de 0,9 e $0,6 \mathrm{~mm}$ para cada $100 \mathrm{~g} \mathrm{~m}^{-2}$ de bokashi, nos experimentos sem e com adubação inorgânica no plantio, respectivamente (Figura 1C). Os valores observados foram pouco inferiores aos de Silva et al. (2016) que avaliaram a influência de doses de torta de mamona aplicadas em cobertura na produção de beterraba, com adubação orgânica apenas no plantio, e obtiveram comprimento de $57 \mathrm{~mm}$. Magro et al. (2015) obtiveram comprimento de $64,9 \mathrm{~mm}$ ao avaliarem a produção e a qualidade da beterraba sob diferentes doses de composto orgânico no plantio e fertilização potássica em cobertura.

O diâmetro da raiz também aumentou linearmente em função das doses de bokashi aplicado, nos dois experimentos. O maior valor estimado foi $55,4 \mathrm{~mm}$, sem adubação inorgânica e com a presença desta adubação foi de $57,6 \mathrm{~mm}$, na dose de $600 \mathrm{~g} \mathrm{~m}^{-2}$. O aumento foi de 1,4 e $1,3 \mathrm{~mm}$ para cada $100 \mathrm{~g} \mathrm{~m}^{-2}$ de bokashi, sem e com adubação inorgânica de plantio, respectivamente (Figura 1D). Corrêa et al. (2014), Magro et al. (2015) e Silva et al. (2016) obtiveram diâmetros de 65,6 mm 58,9 $\mathrm{mm}$ e $65 \mathrm{~mm}$ de raiz de beterraba, respectivamente. $\mathrm{O}$ tamanho das beterrabas obtidas nos trabalhos citados, assim como neste experimento são classificados para comercialização como Extra A (2A), pois apresentam diâmetro entre 50 e 90 mm (CEAGESP, 2017).

Para a produtividade, quanto maior a dose em cobertura $\left(600 \mathrm{~g} \mathrm{~m}^{-2}\right)$, maiores as produtividades, resultando em 19,5 e 22,9 $\mathrm{Mg} \mathrm{ha}^{-1}$ nos experimentos sem e com adubação inorgânica no plantio, respectivamente. $\mathrm{O}$ aumento foi de 0,9 e $1,1 \mathrm{Mg} \mathrm{ha}^{-1}$ para cada $100 \mathrm{~g} \mathrm{~m}^{-2}$ de bokashi, sem e com adubação inorgânica no plantio, respectivamente (Figura 1E). A maior produtividade de raiz de beterraba obtida por Oliveira et al. (2012) foi de $42 \mathrm{Mg} \mathrm{ha}^{-1}$ e por Corrêa et al. (2014) de $35 \mathrm{Mg} \mathrm{ha}^{-1}$. Os primeiros autores avaliaram urina de vaca na produção de beterraba, enquanto o segundo trabalho citado estudou espaçamento. Estes resultados foram diferentes ao desta pesquisa, demonstrando que doses superiores poderiam aumentar a produtividade, visto que houve efeito linear.

Trabalhos com adubação de cobertura orgânica são raros e os resultados obtidos no presente estudo auxiliam na tomada de decisão de quanto usar desta fonte, visando a produtividade igual ou próxima de uma fonte inorgânica, beneficiando tanto os produtores orgânicos, como produtores convencionais que buscam a revitalização dos solos.

Salienta-se que a produtividade foi calculada multiplicando-se a massa média de raiz pela população de plantas (307.692 plantas ha ${ }^{-1}$ ), que foi estimada pelo espaçamento entre linhas de $0,25 \mathrm{~m}, 0,10 \mathrm{~m}$ entre plantas e o espaçamento entre canteiros $0,30 \mathrm{~m}$. No entanto, nem sempre os autores consideram o espaçamento entre canteiros para o cálculo da produtividade em beterraba, obtendo estimativas superestimadas, fato que dificulta a comparação.

O bokashi tem a função importante de estimular o aumento de microrganismos que vivem no solo e estes microrganismos decompõem a matéria orgânica disponibilizando nutrientes para as plantas. Em temperaturas maiores a atividade microbiológica é mais intensa. Logo, a incorporação do adubo e temperaturas mais elevadas favorecem a eficiência do bokashi. No presente trabalho, a adubação de cobertura foi feita sobre a superfície do solo, não sendo incorporada e a temperatura durante o experimento foi baixa (média $=16,6{ }^{\circ} \mathrm{C}$ ). Nestas condições a aplicação de até $600 \mathrm{~g} \mathrm{~m}^{2}$ de bokashi, correspondente a $6,0 \mathrm{Mg} \mathrm{ha}^{-1}$, proporcionou maior altura de planta, massa fresca da raiz, comprimento, diâmetro e produtividade da beterraba. Com a ausência de um ponto de máxima para as características avaliadas, estudos com doses mais elevadas de bokashi, assim como sua viabilidade econômica são necessários.

Quanto ao efeito da adubação inorgânica no plantio, não houve diferença entre os experimentos, sem e com adubação inorgânica, pela análise conjunta, para altura de planta e massa da matéria fresca da parte aérea. Entretanto, o experimento no qual foi realizada a adubação inorgânica no plantio apresentou maiores valores de massa da matéria fresca e seca de raiz, massa seca da parte aérea, comprimento, diâmetro da raiz e produtividade (Tabela 3 ). 
Tabela 3. Altura de planta (AP), massa da matéria fresca (MFPA) e seca (MSPA) da parte aérea, massa da matéria fresca (MFR) e seca (MSR) da raiz, comprimento (CR) e diâmetro da raiz (DR) e produtividade (PRO) das plantas de beterraba, nos experimentos com e sem adubação inorgânica no plantio. FCA/UNESP, São Manuel-SP, 2012.

\begin{tabular}{lcccccccc}
\hline $\begin{array}{l}\text { Adubação inorgânica } \\
\text { de plantio }\end{array}$ & $\begin{array}{c}\text { AP } \\
(\mathrm{cm})\end{array}$ & $\begin{array}{c}\text { MFPA } \\
(\mathrm{g})\end{array}$ & $\begin{array}{c}\text { MSPA } \\
(\mathrm{g})\end{array}$ & $\begin{array}{c}\text { MFR } \\
(\mathrm{g})\end{array}$ & $\begin{array}{c}\text { MSR } \\
(\mathrm{g})\end{array}$ & $\begin{array}{c}\text { CR } \\
(\mathrm{mm})\end{array}$ & $\begin{array}{c}\text { DR } \\
(\mathrm{mm})\end{array}$ & $\begin{array}{c}\text { PRO } \\
\left.(\mathrm{Mg} \mathrm{ha})^{-1}\right)\end{array}$ \\
\hline Sem & $21,53 \mathrm{a}$ & $29,00 \mathrm{a}$ & $2,67 \mathrm{~b}$ & $66,2 \mathrm{~b}$ & $9,49 \mathrm{~b}$ & $43,70 \mathrm{~b}$ & $53,11 \mathrm{~b}$ & $20,3 \mathrm{~b}$ \\
Com & $21,87 \mathrm{a}$ & $30,95 \mathrm{a}$ & $3,17 \mathrm{a}$ & $77,3 \mathrm{a}$ & $12,29 \mathrm{a}$ & $46,32 \mathrm{a}$ & $55,19 \mathrm{a}$ & $23,8 \mathrm{a}$ \\
\hline F & $0,44^{\mathrm{ns}}$ & $1,11^{\mathrm{ns}}$ & $4,77^{*}$ & $8,34^{*}$ & $11,95^{*}$ & $6,33^{*}$ & $4,36^{*}$ & $8,34^{*}$ \\
\hline CV $(\%)$ & 8,20 & 21,36 & 27,03 & 18,68 & 25,72 & 9,33 & 6,38 & 18,68 \\
\hline
\end{tabular}

Médias seguidas por mesma letra, nas colunas, não diferem entre si pelo teste de Tukey a 5\% de probabilidade; ns = não significativo pelo teste $\mathrm{F}$ a $5 \%$ de probabilidade; *significativo pelo teste $\mathrm{F}$ a $5 \%$ de probabilidade.

A aplicação conjunta de adubo orgânico e inorgânico foi superior para a maioria das características em relação à adubação apenas orgânica. Para se obter o mesmo resultado da adubação mista (orgânico + inorgânico), apenas com a adubação orgânica, provavelmente as doses no plantio devem ser maiores. Resultados diferentes foram obtidos por Silva et al. (2016) onde a adubação orgânica associada à inorgânica não influenciou nas características avaliadas da beterraba, sendo que apenas a adubação orgânica foi suficiente. O boletim oficial de recomendação de São Paulo recomenda a aplicação de 30 a $50 \mathrm{Mg} \mathrm{ha}^{-1}$ de composto orgânico (TRANI et al., 1997), sendo que como critério de referência neste experimento foi utilizada a dose média de $40 \mathrm{Mg} \mathrm{ha}{ }^{-1}$. No entanto, Magro et al. (2015) obtiveram a máxima produtividade de beterraba com a dose de $52 \mathrm{Mg} \mathrm{ha}^{-1}$ de composto orgânico.

Muitos produtores no sistema convencional costumam realizar a adubação de plantio com a aplicação de adubos orgânicos juntamente com os inorgânicos, o que, geralmente, apresenta bons resultados, como os obtidos neste experimento. Porém, produtores do setor orgânico, não podem utilizar os adubos inorgânicos. É de se esperar, neste caso, que para o mesmo solo, doses superiores de adubo orgânico serão necessárias para obter-se o mesmo resultado.

\section{Conclusões}

A aplicação de até $600 \mathrm{~g} \mathrm{~m}^{-2}$ de bokashi em cobertura incrementou a altura da planta, a matéria fresca das raízes, comprimento de raiz e produtividade da beterraba nos dois experimentos utilizando a adubação inorgânica no plantio e não utilizando.

A adubação de plantio orgânica quando associada à inorgânica apresentou os melhores resultados dos caracteres avaliados, quando comparada à orgânica.

\section{Agradecimentos} bolsa.

\section{Referências Bibliográficas}

BANZATTO, D. A.; KRONKA, S. N. Experimentação agrícola. 4. ed. Jaboticabal-SP: Funep, 2006. 237 p.

BARRETO, C. R.; ZANUZO, M. R.; WOBETO, C.; ROSA, C. C. Produtividade e qualidade da beterraba em função da aplicação de doses de nitrogênio. Revista Uniara, Araraquara-SP, v. 16, p. 146-158, 2013.

CORREA, C. V.; CARDOSO, A. I. I.; SOUZA, L. G.; ANTUNES, W. L. P.; MAGOLBO, L. A. Produção de beterraba em função do espaçamento. Horticultura Brasileira, Brasília-DF, v. 32, n. 1, p. 111-114, 2014.

EMPRESA BRASILEIRA DE PESQUISA AGROPECUÁRIA - EMBRAPA. 2013. Sistema brasileiro de classificação dos solos. 3. ed. Brasília, 2013. 353 p.

FERREIRA, D. F. Sisvar: a computer statistical analysis system. Ciência e Agrotecnologia, Lavras-MG, v. 35, n. 6, p. 1039-1042, 2011.

FILGUEIRA, F. A. R. Novo manual de olericultura: Agrotecnologia moderna na produção e comercialização de hortaliças. 3. ed. Viçosa-MG: UFV, 2008. 421 p.

MAGRO, F. O.; SILVA, E. G.; TAKATA, W. H. S.; CARDOSO, A. I. I.; FERNANDES, D. M.; EVANGELISTA, R. M. Organic compost and potassium top dressing fertilization on production and quality of beetroot. Australian Journal of Crop Science, Australia, v. 9, p. 962-967, 2015.

MAPA. MINISTÉRIO DA AGRICULTURA, PECUÁRIA E ABASTECIMENTO. Manual de métodos analíticos oficiais para fertilizantes e corretivos. Brasília-DF: MAPA, 2014. $220 \mathrm{p}$.

MOOZ, E. D.; SILVA, M. V. Cenário mundial e nacional da produção de alimentos orgânicos. Revista Nutrire, São PauloSP, v. 39, n. 1, p. 99-112, 2014

OLIVEIRA, N. L. C.; PUIATTI, M.; BHERING, A. S.; CECON, P. R.; SILVA, G. C. C. Uso de urina de vaca no cultivo da beterraba de mesa. Revista Brasileira de Agropecuária Sustentável, Viçosa-MG, v. 2, n. 2, p.7-13, 2012.

OURIVES, O. E. A.; SOUZA, G. M.; TIRITAN, C. S.; SANTOS, D. H. Fertilizante orgânico como fonte de fósforo no cultivo inicial de Brachiaria brizantha cv. Marandú. Pesquisa Agropecuária Tropical, Goiânia-GO, v. 40, n. 2, p.126-132, 2010. 
SILVA, P. N. L; LANNA, N. B. L.; CARDOSO, A. I. I. Produção de beterraba em função de doses de torta de mamona em cobertura. Horticultura Brasileira, Brasília-DF, v.34, n. 3, p. 416-421, 2016.

SIQUEIRA, A. P. P.; SIQUEIRA, M. F. B. Bokashi: adubo orgânico fermentado. Niterói-RJ: Programa Rio Rural, 2013. $16 \mathrm{p}$.

SOUZA, J. L.; RESENDE, P. Manual de horticultura orgânica. 3. ed. Viçosa-MG: Aprenda Fácil, 2014. 841 p.
TIVELLI, S. W., FACTOR, T. L.; TERAMOTO, J. R. S.; FABRI, E. G.; MORAES, A. R. A.; TRANI, P. E.; MAY, A. Beterraba: do plantio a comercialização. Campinas-SP: Instituto Agronômico, 2011. 45 p.

TRANI, P. E.; PASSOS, F. A.; TAVARES, M.; AZEVEDO FILHO, J. A. Beterraba, cenoura, nabo, rabanete e salsa. In: RAIJ, B. VAN; CANTARELlA, H.; QUAGGIO, J. A.; FURLANI, A. M. C. Recomendações de adubação e calagem para o Estado de São Paulo. 2. ed. Campinas-SP: Instituto Agronômico \& Fundação IAC, 1997. 285 p. 